\title{
Revista
}

\section{A PESQUISA NA FORMAÇÃO CONTINUADA DE PROFESSORES: POSSIBILIDADES E LIMITES}

\section{RESEARCH IN TEACHERS CONTINUING EDUCATION: POSSIBILITIES AND LIMITS}

\author{
katia Mosconi Mendes
}

\begin{abstract}
RESUMO
O presente artigo apresenta uma pesquisa que teve como objeto de estudo a formação continuada dos professores da educação infantil e séries iniciais do ensino fundamental da Rede Municipal de Ensino de Curitiba, que acontece no Projeto Escola \& Universidade, uma parceria entre universidade e escola voltada à formação continuada de professores. Os resultados do estudo apontam que a formação continuada ainda está distante de ser um processo contínuo, em que o professor esteja envolvido não só como expectador, mas como protagonista de um processo de estudos e produção de conhecimentos em educação. Desvela-se, a partir dos depoimentos dos participantes da pesquisa, que o Projeto Escola e Universidade, dadas as circunstâncias em que se desenvolve, não supera a racionalidade técnica na orientação da ação docente e mantém a prática docente na perspectiva de reprodutora do conhecimento. A promessa da pesquisa na escola, com apoio da universidade, não avança para além de descrever de forma restrita os problemas da prática pedagógica. A escola como lócus de formação continuada e o cotidiano pedagógico como oportunidade para o desenvolvimento de pesquisa pelo professor significa transitar entre um sistema que insiste manter o ensino com base na reprodução do conhecimento e menos na possibilidade da produção de conhecimento.
\end{abstract}

Palavras-chave: Escola e Universidade. Formação continuada de professores. Prática do professor. Pesquisa na formação do professor.

\begin{abstract}
This article presents a study that had as its object of study the teachers continuing education at elementary school and initial grades in the Municipal Education Section of Curitiba, held at Project School \& University, a partnership between university and school oriented to teachers continuing education. The study results indicate that the developed continuing education is still far from being a continuous process, in which the teacher is involved not only as a spectator, but as the protagonist of a process of research and production of knowledge in education. Unveils itself from the testimony of the respondents that the School and University Project, given the circumstances in which it develops, does not overcome the technical rationality in guiding the teaching action and keeps teaching practice from the perspective of reproductive knowledge. The promise of research in school, with support from the university, does not advance beyond narrowly describe the problems of teaching practice. The school as a place of continuing education and teaching everyday as an opportunity for the development of research by Professor mean transit between a system that insists to keep teaching based on the reproduction of knowledge and less on the possibility of knowledge production.
\end{abstract}

Keywords: School and University. Teachers' Continuing Education. Teacher Practice. Research in teacher education. 


\section{INTRODUÇÃO}

formação continuada aparece com destaque nas discussões educacionais, uma vez que a
formação inicial tem sido considerada insuficiente para instrumentalizar o professor a
lidar com a complexidade que envolve sua relação com o saber e o seu papel como mediador entre o conhecimento a ser construído e seus alunos.

O presente texto apresenta pesquisa desenvolvida que teve como objetivo contribuir para a reflexão sobre os pressupostos teóricos que norteiam a formação continuada de professores da educação infantil e anos iniciais do ensino fundamental da RME de Curitiba, tendo como lócus o Projeto “Escola \& Universidade”, criado pela SME de Curitiba.

Foram tomados como referências os pressupostos da pesquisa na formação dos professores (ANDRÉ, 2006; BEILLEROT, 2006; KUENZER, 1999; MOLINA, 2007), procurando situar o projeto no contexto da formação continuada, buscando indicativos para a análise sobre a superação do modelo da racionalidade técnica em um projeto que se nomeia como investigação-ação.

A pesquisa-ação requer planejamento, discussões, coleta de dados e ações que dependem de uma série de condições. Vem dessa premissa a questão que norteou o desenvolvimento da presente pesquisa: O “Escola \& Universidade” supera o modelo da racionalidade técnica? Essa proposta traz contribuições à prática do professor?

\section{METODOLOGIA}

Para a realização da pesquisa de natureza qualitativa foram utilizados como procedimentos: investigação por meio de questionário junto a 26 professores e pedagogos da Rede Municipal de Ensino de Curitiba que desenvolveram projetos; e também entrevistas com 15 professores e pedagogos da Rede municipal de Ensino de Curitiba e professores-orientadores da IES selecionada para a pesquisa que desenvolveram projetos.

A opção por selecionar esse número de profissionais da rede baseou-se no percentual de cerca de 8\% dos 495 profissionais da educação orientados nos projetos desenvolvidos no ano de 2005 e 2006 pela IES, campo desta pesquisa.

\section{O PROJETO ESCOLA \& UNIVERSIDADE}

Oferecido pela SME de Curitiba desde 1998, inicialmente nomeado como Programa “Fazendo Escola”, o Projeto "Escola \& Universidade” é caracterizado como investigação-ação, no 
qual universidade e escola trabalham em parceria buscando diminuir o distanciamento entre pesquisa acadêmica e prática docente por meio de diálogo e colaboração entre pesquisadores e professores para construir conhecimentos sobre a educação. É um programa que visa estimular os profissionais da educação que atuam nas escolas da Rede Municipal para elaborar e desenvolver projetos que promovam a melhoria na qualidade do ensino.

Para o desenvolvimento do projeto, anualmente, em média, são ofertadas 2500 bolsas auxílio aos professores, sendo a operacionalização feita em parceria com seis IES de Curitiba que analisam, selecionam, classificam e orientam os professores da Rede Municipal de Ensino durante o desenvolvimento dos projetos.

\subsection{CONCEPÇÕES, CONTRIBUIÇÕES E DIFICULDADES}

A pesquisa da própria prática surge como alternativa para a construção de novas formas de entendimento dos processos escolares a partir daqueles que atuam dentro da escola (MOLINA, 2007, p.13)

Encontrar soluções aos problemas reais significa a problematização da prática. Por isso, buscou-se verificar se os temas propostos partiam da prática do professor, proposição esta que aparece como objetivo do "Escola \& Universidade”.

Podemos apontar três agrupamentos de temas a partir das respostas dos 41 participantes:

- temas que possam motivar os alunos;

- temas que são trazidos dos trabalhos de conclusão de curso e monografias;

- temas pensados a partir das dificuldades dos alunos.

O resultado da pesquisa revelou que as preocupações presentes no cotidiano do professor dizem respeito ao seu fazer pedagógico cotidiano. A problematização da prática como caminho para a construção de conhecimentos em educação não está presente nas respostas de professores e pedagogos. Entre outras questões, o que se busca são respostas rápidas para os enfrentamentos da sala de aula, quer para motivar os alunos por meio do emprego de atividades inovadoras ou para buscar respostas práticas para a superação das dificuldades em sala de aula.

Sob essa perspectiva, a investigação-ação na formação do professor, e no caso do professor pesquisador, pressupõe reflexão crítica por parte deste sobre sua própria prática, ou seja, a análise e problematização da prática e produção de conhecimento pela pesquisa da própria prática.

Já no início do processo para a participação no "Escola \& Universidade” existe inadequação da proposta quando os professores não definem seus temas a partir das dificuldades da prática. 
Pode-se inferir a partir desse dado que os temas pensados não vão além de cumprir uma das etapas do processo para participar do projeto ou, quando muito, buscam respostas fáceis para o enfrentamento das aulas.

\subsubsection{As dificuldades no desenvolvimento do projeto}

Em relação às dificuldades encontradas para desenvolver o projeto, as respostas foram agrupadas da seguinte forma:

- tempo para o desenvolvimento do projeto e para realização de leitura;

- espaço/tempo para aplicação das atividades do projeto e discussão a respeito do projeto na escola;

- falta de apoio da equipe pedagógica (indisponibilidade de materiais, falta de recursos e compreensão para desenvolvimento das atividades elaboradas para o projeto)

- acesso aos referenciais teóricos para consulta do professor;

- envolvimento dos professores da RME no projeto.

A grande preocupação com a forma como os projetos são elaborados, a falta de leituras necessárias para construção de um suporte teórico, dificultam a definição do problema e objetivos da pesquisa a ser desenvolvida no “Escola \& Universidade”.

A preocupação demonstrada pelos professores orientadores aponta mais para a necessidade de uma formação para a pesquisa do que uma preocupação com o rigor ao se fazer pesquisa.

\subsubsection{Contribuições do projeto}

Entre os depoimentos de professores e pedagogos, que participaram da pesquisa, aparecem como contribuições do referido projeto:

- prática de atividades criativas, diferentes e inovadoras;

- oportunidade ao professor a repensar a sua prática;

- aprofundamento de estudos;

- incentivo para buscar uma pós-graduação; 
A contribuição do projeto consiste em aprimoramento, aperfeiçoamento e aprendizagem de novas atividades para aplicar em sala. Aponta, também, para uma forte permanência da racionalidade técnica na formação dos professores.

\section{CONSIDERAÇÕES}

Olhar para a formação continuada implica preocupar-se com que essa vá além de ser instrumento para implantar mudanças na escola, levando em conta o desenvolvimento do professor em âmbito profissional e pessoal e que não tenha vistas apenas à “capacitação” de recursos humanos para educar.

O panorama indicado pela pesquisa é de que o impacto deste projeto no desenvolvimento profissional do professor não vai além da busca de respostas rápidas para as necessidades da prática cotidiana. O projeto não é percebido como formação continuada e possibilidade de pesquisa, mas como algo que poderá trazer soluções rápidas e pontuais às necessidades da prática imediata, sendo indício da permanência da racionalidade técnica como direcionadora da formação docente.

A formação centrada no individualismo, sem a participação coletiva, é uma característica da racionalidade técnica. Os encontros promovidos para a formação continuada neste modelo não possibilitam a reflexão, troca de experiências para socialização de resultados entre os participantes. Esta característica também pode ser verificada no "Escola \& Universidade”, embora tenha como proposta o trabalho cooperativo entre professores e pedagogos da escola.

Observou-se que o processo de escrita do projeto pelos professores apresenta problemas estruturais. Como os professores não entendem que o que vão desenvolver é uma pesquisa, uma investigação-ação, ao elaborarem o projeto não o articulam com problemas da sua prática pedagógica. Os dados apontam que essa dificuldade de escrita é consequência, provavelmente, de uma formação insuficiente e também da falta de recursos e oportunidades que eles têm para realizar estudos contínuos.

Não foram encontrados indícios na pesquisa de que o "Escola \& Universidade" supere, da forma como foi concebido e é desenvolvido, o modelo da racionalidade técnica, a despeito de ser uma proposta de investigação-ação.

A concretização do "Escola \& Universidade” como pesquisa na escola compreenderia mudanças em alguns procedimentos que favorecem práticas hierárquicas entre teoria e prática. Fazse necessário evitar que as concepções, ações e discussões estejam centralizadas nas equipes de SME que cuidam da formação continuada de professores e do "Escola \& Universidade”, pois esta 
prática reforça no professor a ideia de separação entre teoria e prática, que na perspectiva tecnicista quer dizer quem tem poder concebe, quem não dispõe de poder, executa.

Somando-se a essa questão, há que se possibilitar, entre outras condições, espaços para a reflexão crítica e coletiva, que precisa necessariamente acontecer na escola, pois é nesse espaço que a docência se desenvolve. Dadas as condições de trabalho do professor, a forma como o projeto se desenvolve, é improvável que se processem transformações na prática do professor e se constitua em pesquisa da prática pedagógica.

Ressalta-se que o projeto envolve uma parcela que representa 25\% dos profissionais da educação, já que do universo de aproximadamente 11.000 professores na RME, apenas 2.500 desenvolvem o projeto. Assim o projeto apresenta uma contribuição restrita, pois atinge uma minoria.

Uma possibilidade de superação dos limites da pesquisa sobre a prática do professor, limites aqui apontados, seria a ressignificação e reorganização do projeto pela SME feita a partir de discussões com professores e orientadores das IES, isto é, envolver aqueles que estão diretamente participando do projeto. Isto poderia indicar novos caminhos para trazer o projeto para a escola, pensar e organizar o espaço escolar possibilitando o desenvolvimento deste com a participação de toda a comunidade escolar, um projeto pensado para além da sala de aula.

Para que seja possível superar a racionalidade técnica, a pesquisa precisa ser vista como princípio epistemológico, uma vez que envolve a construção do conhecimento por meio da reflexão e análise sobre a realidade. O princípio de formação por realizar pesquisa implica compreender a pesquisa como processo educativo, pois uma formação baseada na pesquisa da prática oportuniza o desenvolvimento de conceitos, habilidades e atitudes de investigação.

Em relação à formação continuada do professor da Rede Municipal de Curitiba, a pesquisa desenvolvida quer aliar-se ao alerta presente em inúmeros estudos, entre estes os encontrados nos referenciais teóricos que iluminaram a interpretação e análise dos dados e reforçar a necessidade da definição de políticas públicas na consolidação da formação continuada dos professores.

Além desta mudança de concepção é fundamental ainda:

- envolver no projeto Escola \& Universidade necessariamente toda a comunidade educativa da escola envolvida num projeto de pesquisa. O projeto perderia o foco na individualização para um processo de formação coletiva, envolvendo a equipe pedagógica; direção; professores e alunos;

- entender e defender o Projeto, ou seja, a pesquisa do professor na escola como algo a ser desenvolvido continuamente, por oportunizar que o professor pesquise a prática 
e poderá contribuir para que passe a trabalhar de modo mais reflexivo e questionador;

- possibilitar na escola espaços de discussão em que seja possível a reunião dos professores para a análise e avaliação constante do desenvolvimento do projeto e os resultados, das mudanças e dos processos;

- utilizar os recursos das bolsas auxílio e outros que a prefeitura possa dispor, como forma de remunerar todos os professores nas escolas pelas horas de trabalho destinadas à formação continuada e para o desenvolvimento do Projeto;

- oportunizar ao professor o diálogo entre sua prática e os fundamentos teóricos que fundamentam a prática educativa. Nessa perspectiva, a realização do Projeto precisa estar orientada pela ação colaborativa entre pesquisadores e professores desde o início da elaboração do Escola \& Universidade para que entre outras questões as necessidades da prática sejam identificadas pelos professores e norteiem a proposição do projeto a ser desenvolvido em cada escola;

- vislumbrar a parceria entre Universidade e Escola em nível institucional e não individual, em que um professor ou professores de um determinado departamento trabalham de forma descontinuada e esporádica com alguns professores da RME. A parceria com as universidades então deverá ser utilizada para que os professores, no caso os orientadores das IES, estejam na escola com os professores, desenvolvendo projetos coletivos e promover discussões críticas, oferecendo subsídios teóricos para análise da prática pedagógica quer na elaboração e desenvolvimento do projeto, quer nas práticas em sala de aula;

- contribuir com a direção e a equipe pedagógica para organizar e gerenciar o processo de formação em serviço e nisso inclua-se o Projeto Escola \& Universidade, pois quanto maior for o envolvimento da equipe maiores serão as possibilidades de que mudanças significativas aconteçam na escola.

É imprescindível que se tenha uma política comprometida com a valorização do magistério e que promova a formação continuada de professores voltada ao desenvolvimento pessoal e profissional do professor.

Não é demais indicar que os problemas da prática do professor precisam ser considerados como ponto de partida no desenvolvimento das ações de formação continuada em serviço.

Para que os programas de formação continuada possam ter sucesso, quer na escola preferencialmente ou fora dela, é necessário que se garantam algumas condições. Uma primeira condição seria valorizar os professores, respeitá-los e ouvi-los em suas necessidades e experiências. 
Outro ponto importante seria a equipe pedagógica considerar a formação continuada como condição e possibilidade de desenvolvimento pessoal e profissional do professor, e não apenas como forma de trazer inovações para a sala de aula. É necessário, portanto, defender e organizar no espaço escolar oportunidades para os professores poderem se encontrar com seus pares para analisar e refletir sobre sua prática e trocar experiências.

Requer-se ainda que o planejamento da formação continuada em serviço seja repensado no sentido de garantir melhores condições para o desenvolvimento do docente, que os professores possam ter então acesso a produções teóricas reconhecidas e atuais, condições de trabalho e bolsa de ajuda de custo, mas não como é operacionalizada no Projeto Escola \& Universidade em que se investe anualmente cerca de $\mathrm{R} \$ 3.000 .000$ (três milhões) em um programa que pouco tem contribuído para a transformação da prática do professor e seu desenvolvimento pessoal e profissional.

Os dados desta pesquisa mostram que as contribuições do Projeto Escola \& Universidade não tem ido além de trazer atividades inovadoras para a sala de aula. Um programa é esvaziado de sentido, quando:

- não tem promovido o desenvolvimento pessoal e profissional do professor;

- o trabalho cooperativo e interdependente entre professores e pedagogos não acontece no desenvolver do projeto;

- a parceria com as IES não tem contribuído com o ‘aprimoramento” teórico e metodológico do professor uma vez que a prática pela prática se esgota se não há possibilidade de se construir conhecimentos sobre essa prática;

- a investigação ação é substituída por práticas que dizem respeito a colocar em curso projetos de ensino.

A pesquisa aponta que os programas de formação continuada e, especificamente, o Projeto Escola \& Universidade, continuam reproduzindo o modelo tradicional baseado na transmissão de informação que tem cunho fundamentalmente teórico em que a ênfase é posta na formação do técnico que deverá ser capaz de agir conforme prescrição feita por quem não está na escola. Nessa perspectiva, o Projeto Escola \& Universidade não supera o modelo de formação continuada com base na racionalidade técnica.

\section{REFERÊNCIAS}

ANDRÉ, M. E.D.A. Pesquisa formação e prática docente. In: ANDRÉ, M. E. D. A. (Org.) O papel da pesquisa na formação e na prática dos professores. São Paulo: Papirus, 2006. p. 55 - 69.

BEILlEROT, J. A Pesquisa: esboço de uma análise. In: ANDRÉ, M. E. D. A. (Org.) O papel da pesquisa na formação e na prática dos professores. São Paulo: Papirus, 2006. p. 71 - 90. 
KUENZER, A. Z. As políticas de formação: a construção da identidade do professor sobrante. Educação e Sociedade, Campinas, ano 20, n. 68,p. 163-183, 1999.

LÜDKE, M.; ANDRÉ, M.E.D.A. Pesquisa em Educação: abordagens qualitativas. 9. ed. São Paulo: EPU, 2001.

MOLINA, R. A Pesquisa-ação / investigação ação no Brasil: mapeamento da produção (19662002) e os indicadores internos da pesquisa-ação colaborativa. 2007. Tese (Doutorado em Educação) - Universidade de São Paulo, São Paulo 2007. 